\title{
Risk factors of the musculoskeletal and joint pains among employees who work with computer in Rafsanjan city in the years 2012-13
}

\author{
Shahimoradi D, $\mathrm{MSc}^{1}$, Vazirinejad $\mathrm{R}, \mathrm{PhD}^{2 *}$ \\ 1- Faculty Member, Dept. of Basis Science, Medical School, Rafsanjan University of Medical Sciences, Rafsanjan, Iran. \\ 2- Professor, Social Determinants of Health Research Centre, Medical School, Rafsanjan University of Medical Sciences, \\ Rafsanjan, Iran.
}

\begin{abstract}
Received: September 2013, Accepted: March 2014

Background: Today application of computer in the life of people is very common and those who work with computer in especially long - term are faced with musculoskeletal pains. The aim of this study was to investigate risk factors of musculoskeletal and Joint pains among computer users in Rafsanjan city in the years 2012-13.

Materials and Methods: In this descriptive study, 420 computer users were recruited in Rafsanjan city between 18 April 2012 and 19 January 2013. The data were collected by a checklist, in face to face interview sessions. Data were analyzed in SPSS and parametric and nonparametric tests were used where appropriate.

Results: Cervical pain was associated with position of desk, chair and keyboard. There were significant association between shoulder pain and position of the keyboard, low back pain and chair position, carpal tunnel syndrome and mouse usage. The prevalence of cervical pain, shoulder pain, arm pain, wrist pain, hand pain, low back pain, elbow pain, back pain, and carpal tunnel syndrome, among respondents were $38.3 \%, 38.3 \%, 27.1 \%, 21.2 \%, 18.8 \%, 24.5 \%, 15.7 \%, 26.4 \%$ and $21.2 \%$, respectively. In this study, there was significant association between exercise and all variables of carpal tunnel syndrome, elbow pain, back pain, low back pain and shoulder pain.

Conclusions: It can be concluded that prevalence of musculoskeletal pain in computer users in our study were very common. Improving the position of desk, chair, mouse and keyboard could help with reducing cervical pain, shoulder pain, back pain, low back pain and carpal tunnel syndrome.
\end{abstract}

Key words: Musculoskeletal Pains, Employees, Risk Factors, Iran.

\section{Introduction}

The applications of computers in the lives of human beings are very important (1-4). Many people work with computers for many years and this can generate musculoskeletal pains such as neck pain, arm pain, elbow pain, wrist pain, finger pain, low back pain and back pain. Therefore knowing about risk factors of working with computer is very important (5-10). Risk factors such as high workload, repetitive movement, posture of sitting, angle of vision, position of the desk and chair, height of keyboard and monitor and overuse of mouse threatens the health of computer users (11-14). Ergonomy science could help with reducing the effect of human factors as well as workplace factors on human health $(1,5,15-17)$. Adedoyin and colleagues, in 2005, confirmed the musculoskeletal pain associated with the use of computer systems in Nigeria. The results

\footnotetext{
${ }^{*}$ Corresponding author: Reza Vazirinejad, Social Determinants of Health Research Center, Rafsanjan University of Medical Sciences, Rafsanjan, Iran. Email: rvazirinejad@yahoo.co.uk
} 
of their study indicated that low back pain and neck pain were found to be the most common pain with $74 \%$ and $73 \%$ respectively. Wrist pain, fingers pain and shoulder pain were 67\%, 65\% and 63\% respectively (4) Zeida and colleagues in Poland studied musculoskeletal pains among 477 computer users. Their findings revealed that the most prevalent complains were neck pain, (55.6\%) arm pain, (26.9\%), elbow, $(13.3 \%)$, wrist-hand $(29.9 \%)$, upper back, (49.6\%) and low back pain, (50.1\%). These pains were significantly related to factors such as bad sitting position (8). Warested studied the association between computer work and neck and upper extremities disorders. The results showed that computer work and these disorders were not associated (18). Ranasinghe and colleagues in 2011 in Srilanka studied complaints of arm, neck and shoulders (CANS) among 2210 computer users. Their findings revealed one-year prevalence of CANS was $56.9 \%$. the most common parts of users body which were affected were forearm - hand, (42.6\%), followed by neck, $(36.7 \%)$ and shoulder-arm, $(32.5 \%)$. The prevalence of work-related CANS among computer office users in Sri Lanka was high and comparable to this prevalence in developed countries. Also, musculoskeletal pains were associated with the work station (desk and chair), poor body posture and long sitting (1).

Jmker concluded that no association was found between the software -recorded duration of computer use at work and the onset of severe arm-wrist - hand and neckshoulder symptoms (11). Bleeker and colleagues studied medical-ergonomic program for symptomatic keyboard -mouse on 56 users in 2011. They concluded that common ergonomic stressors were typing /musing technique, keyboard height, inadequate seating and lack of breaks.
Improvement occurred in $89 \%$ following medical-ergonomic intervention (14). Kanchanomadi and colleagues studied risk factor for the onset and persistence of neck pain in undergraduate students in one year prospective cohort study in 2011. They revealed that neck pain is quite common among under graduate students. In the recruited sample (684 students), 46\% reported the onset of neck pain between baseline and 1-year follow up, of whom 33\% reported persistent neck pain (19). Knowledge about risk factors among computer users is necessary because the factors cause musculoskeletal and joint pain that sometimes intensity of pain is so much severe that causes absenteeism from work, reduction in productivity, poor quality of life and escalating medical expenses (16-18). As far as it is known there has not been any research in our country and also results of the foreign studies are controversial and conflicting $(1,12,18,20)$. Thus the aim of this study was to study the risk factors of the musculoskeletal and Joint pains of computer employees users in Rafsanjan in 2012-13 years.

\section{Materials and Methods}

This descriptive study was carried out on 420 computer users who were employed in Rafsanjan city between 18 April 2012 and 19 January 2013.

The sample size was calculated based on a confidence interval of also since, one of our aims in this research was to estimate it prevalence of musculoskeletal disorders among computer users in the city, we used a proportion calculated in similar studies. So the total sample size was determined as 420 (1-5). A multistage sampling method was applied. The city of Rafsanjan has 59 offices including 4492 employees of which $30 \%$ were eligible for this study (19 offices). By 
referring to the manager's and colleagues, and offices, the questionnaires were completed and the data was collected.

Questionnaire included two sections asking about demographic characteristics and some risk factors such as position of desk, chair, keyboard, mouse, monitor, working time of the day, duration of working year in each, break time, body posture, musculoskeletal pain such as cervical pain, shoulder, arm, elbow, wrist, hand and fingers pain, absence of computer user due to job diseases, performed treatment and daily exercise (1-5, 19-20). Exclusion criteria included the history of rheumatoid arthritis, osteoarthritis connective tissue lesions, surgery, fractures of spine and upper extremity. Inclusion criteria included working with the computer more than 1 year, and working more than 4 hours on a day. Proper working station (desk and chair) was considered in a way that posture of human body is without deviation to sides and kyphosis. Distance of monitor from eye must be 50 centimeters. The keyboard should be at elbow level and 15 centimeters bellow desk. Computer users must have rest time for 10 minutes after 50 minutes working. Also at this time computer users should have exercise of neck, shoulder, elbow, wrist, fingers, low back, knees and ankles (18-22). The data were kept confidential, anonymous and were analyzed using SPSS version $15^{\text {th }}$.

\section{Results}

The study included 420 respondents, of which $300(71.4 \%)$ were men and 120 $(28.6 \%)$ were women with a mean age of $38.8 \pm 9.6$ years. The most prevalent musculoskeletal pain in subjects included cervical pain, (161 cases, 38.3\%), and shoulder pain (161 cases, 38.3\%) (Table1).
Body posture in 334 (79.5\%) of respondents at work was proper and 86 respondents (20.5\%) had bad posture. Position of elbow in 283 cases $(67.4 \%)$ was good and in 137 (32.6\%) was not proper. Forty eight $(11.4 \%)$ subjects have been absent from work due to the pain and 372 (88.6\%) have not. Medications used for computer users including drug therapy, 162 cases $(38.5 \%)$, physiotherapy 88 cases $(21 \%)$ and 170 (40.5\%) of subjects who had experienced absenteeism from work had not received any treatments. Twenty eight (6.7\%) respondents were aware of the science of ergonomic and $392(93.3 \%)$ of them were not aware of this science.

Table 1: Distribution of respondents based on the musculoskeletal pain in computer users

\begin{tabular}{ccccc}
\hline \multirow{2}{*}{ Musculoskeletal pain } & \multicolumn{2}{c}{ Yes } & \multicolumn{2}{c}{ No } \\
\cline { 2 - 5 } & $\mathbf{N}$ & \% & N & \% \\
\hline Neck pain & 161 & 38.3 & 259 & 61.7 \\
Shoulder pain & 161 & 38.3 & 259 & 61.7 \\
Arm pain & 114 & 27.1 & 306 & 72.9 \\
Wrist pain & 89 & 21.2 & 331 & 78.8 \\
Hand pain & 79 & 18.8 & 341 & 81.2 \\
Low back pain & 124 & 29.5 & 269 & 70.5 \\
Elbow Pain & 66 & 15.7 & 354 & 84.3 \\
Back pain & 111 & 26.4 & 309 & 73.6 \\
Carpal tunnel & 89 & 21.2 & 331 & 78.8 \\
syndrome & & & & \\
\hline
\end{tabular}

As it can be seen in Table 2 the difference between the presence or absence of proper desk and neck pain was significant. So that the case of neck pain in 34 (34\%) respondents had proper desk and in 124 (40\%) of them had improper desk $(\mathrm{P}<0.05$, df $\left.=1, \chi^{2}=4\right)$. Also, between seating position and neck pain there was a significant statistical association. Among respondents with neck pain $53(33 \%)$ respondents had proper chair and $108(41.5 \%)$ had improper chair $(\mathrm{P}<0.05$, $\mathrm{df}=1, \chi^{2}=3.6$ ). 
Table2: Distribution of respondents with different types of pain based on the existence of risk factors

\begin{tabular}{|c|c|c|c|c|c|c|c|c|c|c|}
\hline \multirow[t]{2}{*}{$\begin{array}{l}\text { Risk factor } \\
\text { Type of pains }\end{array}$} & \multicolumn{2}{|c|}{$\begin{array}{c}\text { Position of } \\
\text { desk }\end{array}$} & \multicolumn{2}{|c|}{$\begin{array}{l}\text { Position of } \\
\text { chair }\end{array}$} & \multicolumn{2}{|c|}{$\begin{array}{l}\text { Place of } \\
\text { keyboard }\end{array}$} & \multicolumn{2}{|c|}{$\begin{array}{l}\text { Position of } \\
\text { mouse }\end{array}$} & \multicolumn{2}{|c|}{$\begin{array}{l}\text { Position of } \\
\text { monitor }\end{array}$} \\
\hline & Good & Bad & Good & Bad & Good & Bad & Good & Bad & Good & Bad \\
\hline \multicolumn{11}{|l|}{ Neck Pain } \\
\hline $\mathbf{N}$ & 34 & $124 *$ & 53 & $108^{*}$ & 36 & $125^{*}$ & 78 & 78 & 116 & 44 \\
\hline$\%$ & 34 & 40 & 33 & 41.5 & 31.5 & 41 & 36.3 & 38.3 & 38.2 & 38.3 \\
\hline \multicolumn{11}{|l|}{ Shoulder Pain } \\
\hline $\mathbf{N}$ & 35 & 126 & 56 & 105 & 35 & $126^{*}$ & 75 & 83 & 116 & 44 \\
\hline$\%$ & 32 & 40.5 & 35 & 40.4 & 30.7 & 41 & 36.3 & 40.5 & 38.2 & 38.3 \\
\hline \multicolumn{11}{|l|}{ Elbow pain } \\
\hline $\mathbf{N}$ & 15 & 51 & 21 & 45 & 15 & 51 & 28 & 38 & 44 & 22 \\
\hline$\%$ & 14 & 16.4 & 13 & 17.3 & 13.2 & 16.7 & 13 & 18.5 & 14.5 & 19 \\
\hline \multicolumn{11}{|l|}{ Wrist pain } \\
\hline $\mathbf{N}$ & 22 & 67 & 30 & 59 & 23 & 66 & 40 & 49 & 64 & 25 \\
\hline$\%$ & 20.2 & 21.5 & 19 & 22.7 & 20.2 & 21.6 & 18.6 & 24 & 21 & 21.7 \\
\hline \multicolumn{11}{|l|}{ Arm pain } \\
\hline $\mathbf{N}$ & 25 & 89 & 42 & 72 & 25 & 89 & 54 & 60 & 85 & 28 \\
\hline$\%$ & 23 & 38.6 & 26.3 & 27.7 & 22 & 29 & 25 & 29 & 28 & 24.3 \\
\hline \multicolumn{11}{|l|}{ Hand pain } \\
\hline $\mathbf{N}$ & 17 & 62 & 25 & 54 & 17 & 62 & 36 & 45 & 55 & 30 \\
\hline$\%$ & 15.6 & 20 & 15.6 & 20.8 & 15 & 20.3 & 15.8 & 22 & 18 & 24 \\
\hline \multicolumn{11}{|l|}{ Low back pain } \\
\hline $\mathbf{N}$ & 30 & 94 & 39 & $85 *$ & 21 & $103^{*}$ & 52 & $72 *$ & 87 & 37 \\
\hline$\%$ & 27.5 & 30.2 & 24.4 & 32.7 & 18.6 & 23.7 & 24.2 & 35 & 28.6 & 32.2 \\
\hline \multicolumn{11}{|l|}{ Back Pain } \\
\hline $\mathbf{N}$ & 21 & 90 & 39 & 72 & 17 & $94 *$ & 40 & $71^{*}$ & 73 & 38 \\
\hline$\%$ & 19.3 & 29 & 24.4 & 27.7 & 15 & 30.7 & 18.6 & 34 & 24 & 33 \\
\hline \multicolumn{11}{|l|}{$\begin{array}{l}\text { Carpal tunnel } \\
\text { syndrome }\end{array}$} \\
\hline $\mathbf{N}$ & 16 & 73 & 26 & $63 *$ & 16 & $73 *$ & 38 & $51 *$ & 61 & 28 \\
\hline$\%$ & 15 & 23 & 16.3 & 24.2 & 14 & 24 & 17.7 & 25 & 20.1 & 24.3 \\
\hline
\end{tabular}

*: Difference at level of $\alpha=5 \%$ is significant $N$ : The number of respondents in each group

Between the place of keyboard and neck pain was significant association. In respondents neck pain $36(31.6 \%)$ subjects had proper place of keyboard and $125(41 \%)$ of them had not $\left(\mathrm{P}<0.05\right.$, df $\left.=1 \chi^{2}=3.3\right)$. Between the place of keyboard and shoulder pain was also significant association. Thirty-five (30.7\%) respondents with shoulder pain had proper place of keyboard and in $126(41 \%)$ of them had not $\left(\mathrm{P}<0.05\right.$, df $\left.=1, \chi^{2}=4.8\right)$. The association between seats (chair) and low back pain was significant. Among respondents with low back pain, 39 (24.4\%) Subjects had proper chair and $85(32.7 \%)$ had not $\left(\mathrm{P}<0.05\right.$, df $\left.=1, \chi^{2}=3.1\right)$. The association between place of keyboard and 
low back pain was significant. In 21 (18.4\%) subjects with low back pain the place of keyboard was appropriate and in 103 $(23.7 \%)$ of them was not inappropriate $\left(\mathrm{P}<0.05\right.$, df $\left.=1, \chi^{2}=4\right)$. Also association between the mouse and low back pain was significant. In respondents with low back pain, 52(24.2\%) reported proper position of mouse and in $73(35 \%)$ of them it was improper $\left(\mathrm{P}<0.05\right.$, df $\left.=1, \chi^{2}=9.3\right)$. Between place of keyboard and back pain there was significant association. In respondents with back pain $17(15 \%)$ subject had proper place of keyboard and in 94 (30.7\%) of them it was improper $\left(\mathrm{P}<0.05\right.$, df $\left.=1, \chi^{2}=10.1\right)$. Also association between position of mouse and back pain was significant. Among respondents with back pain, 40(18.6\%) subjects had appropriate position of mouse and in $71(34 \%)$ of them had inappropriate $\left(\mathrm{P}<0.05, \mathrm{df}=1, \chi^{2}=3.3\right)$. Association between position of chair and carpal tunnel syndrome was significant. In respondents with carpal tunnel syndrome, 26(16.3\%) subjects reported proper position of chair and in $63(24.2 \%)$ of them it was improper $(\mathrm{P}<0.05$, $\mathrm{df}=1, \chi^{2}=6$ ).

Also association between place of keyboard and carpal tunnel syndrome was significant. In respondents with carpal tunnel syndrome, $16(14 \%)$ subjects had proper place o keyboard and in $73(24 \%)$ of them it was improper $\quad\left(\mathrm{P}<0.05, \quad\right.$ df $\left.\quad=1, \quad \chi^{2}=13.6\right)$. Association between position of mouse and carpal tunnel syndrome was also significant. Among respondents with carpal tunnel syndrome, 38 (17.7\%) subjects reported proper position of mouse and in 51(25\%) of them it was improper $\left(\mathrm{P}<0.05\right.$, df $\left.=1, \chi^{2}=3.5\right)$. As table 3 shows the association between the presence or absence of exercise and carpal tunnel syndrome was significant. Twentyfive $(14.5 \%)$ respondents with carpal tunnel syndrome reported exercise and $147(85.5 \%)$ of them didn't report it $(\mathrm{P}<0.05$, df $=1$, $\chi^{2}=7.72$ ). Also the association between exercise and elbow pain was significant. Among respondents with elbow pain in $20(11.6 \%)$ reported exercise and 152(88.4) of them didn't $\left(\mathrm{P}<0.05\right.$, df $\left.=1, \chi^{2}=3.4\right)$. The association between exercise and back pain was also significant. In respondent with back pain, $37(22.5 \%)$ subjects reported exercise and $135(78.5 \%)$ of them didn't $(\mathrm{P}<0.05$, df $=1, \chi^{2}=3.6$ ). Between presence or absence of exercise and low back pain there was significant association. Among respondents with low back pain 41 (23.8\%) reported exercise and 131(76.2\%) of them didn't $\left(\mathrm{P}<0.05, \mathrm{df}=1, \chi^{2}=4.52\right)$.

Table 3: Distribution of respondents according to different types of pain and the presence or absence of previous exercise

\begin{tabular}{lcccc}
\hline \multirow{2}{*}{$\begin{array}{c}\text { Exercise } \\
\text { Types of pains }\end{array}$} & \multicolumn{2}{c}{ Yes } & \multicolumn{2}{c}{ No } \\
\cline { 2 - 5 } Carpal Tunnel & $\mathbf{N}$ & $\%$ & $\mathbf{N}$ & $\%$ \\
\hline $\begin{array}{l}\text { syndrome } \\
\text { Elbow pain }\end{array}$ & 25 & 14.5 & $147^{*}$ & 85.5 \\
Back pain & 37 & 22.5 & $135^{*}$ & 78.5 \\
Low back pain & 41 & 23.8 & $131^{*}$ & 76.2 \\
Hand pain & 37 & 21.5 & 135 & 78.5 \\
Wrist pain & 36 & 20.9 & 136 & 79.1 \\
Arm pain & 43 & 25 & 129 & 75 \\
Shoulder pain & 52 & 30.2 & $120^{*}$ & 69.8 \\
Neck pain & 57 & 33.7 & 114 & 66.3 \\
\hline
\end{tabular}

Difference at level of $\alpha=5 \%$ is significant

Also the association between presence or absence of exercise and shoulder pain was significant. Among respondents with shoulder pain $52(30.2 \%)$ subjects did exercise and $120(69.8 \%)$ of them didn't $\left(\mathrm{P}<0.05, \mathrm{df}=1, \chi^{2}=8.08\right)$.

\section{Discussion}

The prevalence of musculoskeletal disorder among men was, $71.4 \%$ and in women was, $28.6 \%$. These results were matched with the 
study of Iwakiri (2). However the results reported by Ranasinghe were different (50.8\% in men, $49.2 \%$ in women). In this study, the prevalence of neck and shoulder pain was $38.3 \%$, this result was similar to what was reported in studies of Ranasighe, Siu and Kanchanomai in which prevalence of neck and shoulder pain were $36.7 \%, 37 \%$, $33 \%$, respectively $(1,15,19)$. However, studies of Adedoyin, Iwakiri reported higher prevalence of this pain as $73 \%$ and $59.3 \%$ respectively $(2,4)$. In this study, the prevalence of arm pain was $27.1 \%$ which was compatible with results of Ranasinghe and zeida $(1,8)$.

The prevalence of low back pain and back pain in our study were $29.5 \%$ and $26.4 \%$ respectively lower than that was reported by Adedoyin that announced low back pain and back pain, for $74 \%$ of computer users. Also study of zeida reported the prevalence of low back pain and back pain, among 50\% $(4,8)$. The prevalence of wrist pain and carpal tunnel syndrome was $21.2 \%$ which was compatible with the result of zeida (8) but were different from the results of Ranasinghe and Adedoin $(1,4)$.

In our study associations between risk factors such as position of desk of computer users, chair (seating) place of keyboard, mouse and neck pain, shoulder pain, low back pain, back pain and carpal tunnel syndrome were significant. This finding was similar to Ranasinghe, Adedoyin, Zieda, Yoo and Kanchanomai $(1,4,8,13,19)$ but was not similar studies of Diepehmoat, Jmker, Andersen, warsted and speckle (7, 11, 12, 18, 20). In our study association between performed exercise and shoulder pain, elbow pain, back pain, low back pain, and carpal tunnel syndrome was significant. Computer users, who didn't exercise, are more susceptible to above mentional pains. These findings are similar to the resulths of studies of YOO, Marangoni and sihawong (13, 21, 22). They reported the positive effects of exercise in improving of musculoskeletal pains due to work with computer. We concluded that prevalence of musculoskeletal pain such as cervical pain, shoulder pain, back pain, low back pain and carpal tunnel syndrome in computer users are associated to risk fators such as improper desk, chair, and mouse, place of keyboard that these pains can cause absent of computer users, as well as expensive treatments and reduction of productivity. It seems that medical intervention and ergonomic education could help with reducing musculoskeletal pains.

\section{Conclusion}

It could be concluded that prevalence of musculoskeletal pains such as neck pain, shoulder pain, back pain, low back pain and carpal tunnel syndrome are high in computer users and they are associated to risk factors such as improper desk of computer, chair, mouse, place of keyboard and these pain can cause absent of computer users, heavy expensive treatments and reduction of productivity.

\section{Acknowledgment}

We would like to thank research council of Rafsanjan University of Medical Sciences.

Conflict of interest: Non declared

\section{References}

1. Ranasinghe P, Perera YS, Lamabadusuriya DA, Kulatunga S, Jayawardana N, Rajapase $\mathrm{S}$, et al. Work related complaints of neck, shoulder and arm among computer office 
workers: a cross-sectional evaluation of prevalence and risk factors in a developing country. Environ Health 2011; 10:70.

2. Iwakiri K, Mori I, Sotoyama M, Horiguchi K, ochiai $\mathrm{T}$, Jonai $\mathrm{H}$, et al. Survey on visual and musculoskeletal symptoms in VDT workers. Sangyo Eiseigaku Zasshi 2004; 46(6):201-12.

3. Juul-kristensen B, Jensen C. Self-reported workplace related ergonomic conditions as prognostic factors for musculoskeletal symptoms: the "BIT" follow up study on office workers. Occup Environ Med 2005; 62(3):188-94.

4. Adedoyin RA, Idowu BO, Adagunodo RE, Owoyomi AA, Idowu PA. Musculoskeletal pain associated with the use of computer system in Nigeria. Technol Health Care 2005; 13(2):125-30.

5. Hakala PT, Rimpela AH, Saarni LA, Salminen JJ. Frequent Computer-related activities increase the risk of neck-shoulder and low back pain in adolescents. Eur J Public Health 2006; 16(5):536-41.

6. Janwantanakul P, Pensri P, Jiamjarasrangsri V Sinsongsook T. Prevalence of self-reported musculoskeletal symptoms amoung office workers. Occup Med (Lond) 2008; 58(6):436-8.

7. Diepenmaat AC, Van der wal MF, de Vet HC, Hirasing RA. Neck/shoulder, Low back, and arm pain in relation to computer use, physical activity, stress, and depression among Dutch adolescents. Pediatrics 2006; 117(2):412-16.

8. Zejda JE, Bugajska J, Kowalska M, Krzych L, Mieszkowska M, Brozek G, et al. Upper extremities, neck and back symptoms in office employees working at computer stations. Med Pr 2009; 60(5):359-67.

9. Hoyle JA, Marras WS, Sheedy JE, Hart DE. Effects of postural and visulal stressors on myofascial trigger point development and motor unit rotation during computer work. J Electromyogr Kinesiol 2011; 21(1):41-8.

10. Malinska M, Bugajska J. The influence of occupational and non-occupational factors on the prevalence of musculoskeletal complaints in users of portable computers. Int J Occup Saf Ergon 2010; 16(3):337-43.

11. Jimker S, Huysmands MA, Van der Beek AJ, Knol DL, van Mechelen W, Bongers PM, et al. Software-recorded and self-reported duration of computer use in relation to the onset of severe arm-wrist-hand pain and neck-shoulder pain. Occup Environ Med 2011; 68(7):502-9.

12. Andersen $\mathrm{JH}$, fallentin $\mathrm{N}$, Thomsen $\mathrm{JF}$, Mikkelsen S. Risk factors for neck and upper extremity disorders among computers users and the effect of interventions: an overview of systematic reviews. PLoS One 2011; 6(5):e19691.

13. Yoo WG, Park SY, Lee MR. Relationship between active cervical range of motion and flexion-relaxation ratio in asymptomatic computer workers. J Physiol Anthropol 2011; 30(5):203-7.

14. Bleecker ML, Celio MA, Barnes SK. A medical-ergonomic program for symptomatic keyboard/mouse users. J Occup Environ Med 2011; 53(5):562-8.

15. Siu DC, Tse LA, Yu IT, Griffiths SM. Computer products usage and prevalence of computer related musculoskeletal discomfort among adolescents. Work 2009; 34(4):44954.

16. Hoy DG, Protani M, De R, Buchbinder R. The epidemiology of neck pain. Best pract Res Clin Rheumatol 2010; 24(6):783-92.

17. Dunk NM, Chung YY, Compton DS, Callaghan JP. The reliability of quantifying upright standing postures as a baseline diagnostic clinical tool. J Manipulative Physiol Ther 2004; 27(2):91-6.

18. Waersted M, Hanvold TN, Veiersted KB. Computer work and musculoskeletal disorders of the neck and upper extremity: A systematic review. BMC Musculoskelet Disord 2010; 11:79.

19. Kanchanomai S, Janwantanakul $P$, pensri $P$, Jiamjarasrangsi W. Risk factors for the onset and persistence of neck pain in undergraduate students: 1-year prospective cohort study. BMC Public Health 2011; 11:566.

20. Spekle EM, Hoozemans MJ, Blatter BM, Heinrich J, Van der Beek AJ, Knol DL, et al. Effectiveness of a questionnaire based intervention programme on the prevalence of arm, shoulder and neck symptoms risk factors and sick leave in computer workers: A cluster randomised controlled trial in a occupational setting. BMC Musculoskelet Disord 2010; 11:99.

21. Marangoni AH. Effects of intermittent stretching exercise at work on musculoskeletal pain associated with the use of a personal computer and influence of media on outcomes. work 2010; 36(1):27-37. 
22. Sihawong R, Janwantanakul P, Sitthipornvorakul E, Pensri P. Exercise therapy for office workers with nonspecific neck pain: a systematic review. J Manipulative Physiol Ther 2011; 34(1):6271. 